\title{
Effect of exercise on serum irisin level in normal and diabetic rats
}

\author{
Hoda Mostafa Ahmed ${ }^{1}$, Amany Abdelrahman Abdelhamid ${ }^{1}$, Zeinab Shaban \\ Mohammed $^{1}$, Nagwa Sayed Ahmed ${ }^{2}$ \\ ${ }^{1}$ Department of Physiology, Faculty of Medicine, Sohag University, Sohag, Egypt. \\ ${ }^{2}$ Department of Medical Biochemistery, Faculty of Medicine, Sohag University, Sohag, \\ Egypt.
}

\begin{abstract}
Background:Exercise is an effective approach for controlling DM. the exact mechanism by which exercise can control DM is still unclear. In 2012, Boström and colleagues discovered that in muscle, exercise increases the expression of FNDC5 (Fibronectin type III domain-containing protein5), amembrane protein encoded by the FNDC5 gene. The FNDC5 protein is cleaved and secreted as a new hormone called irisin suggesting that some of beneficial effects of exercise could be mediated by this hormone. The aim of the study was to estimate effect of exercise on serum irisinand fasting blood glucose levels in normal and diabetic rats.

Material and methods: 120 adult male albino rats were categorized them into 4 groups. Diabetes mellitus was induced by intraperitoneal injection of freshly prepared alloxan monohydrate $(160 \mathrm{mg} / \mathrm{kg})$ in a single dose in Group III and Group IV Physiological saline $(0.9 \% \mathrm{Nacl})$ was injected intraperitoneally in Group Iand Group II.

Fasting blood glucose was measured weekly and two months after swimming exercise serum levels of irisin and insulin were measured.

Results:Exercise increased serum levels of irisin and insulin in both control and diabetic groups alsomeasurement of blood glucose level showed that exercise had decreasing effect on blood glucose in diabetic rats.

Conclusion:Swimming exercise increases serum irisinlevel also improves fasting blood glucose and insulin sensitivityin diabetic rats.

Keywords:Irisin, Exercise, diabetic rat, Fasting blood glucose level.

\section{Introduction}

Diabetes mellitus refers to a group of metabolic diseases characterized by hyperglycemia, caused by defects in insulin secretion, insulin action, or $\operatorname{both}(1)$.

The benefits of good diet and exercise have been extensively documented, and are the cornerstones for nonpharmacological treatment of cardiovascular and metabolic diseases (2). A well-described effect of exercise is 'browning' of white adipose tissue (WAT). In contrast to the primarily fatstoring function of WAT, BAT has non-

shivering thermogenic properties owing to expression of uncoupling protein-1 (UCP1) and increased mitochondrial content(3). Induction of a browning programme in rodents reduces body weight and improves glucose homeostasis (4).

In 2012, Boström and colleagues discovered that in muscle, exercise increases the expression of FNDC5 (Fibronectin type III domain-containing protein 5), a membrane protein encoded by the FNDC5 gene. The FNDC5 protein is cleaved and secreted as a new hormone called irisin suggesting that
\end{abstract}


some of beneficial effects of exercise could be mediated by this hormone. Irisin induces the browning of white adipose tissue (WAT), thereby increasing thermogenesis and possibly improving glucose homeostasis (5).

Exercise is an effective approach for controlling DM. the exact mechanism by which exercise can control DM is still unclear.

Anew hypothesis of signalling pathway (p38-PGC-1 $\alpha$-irisin-betatrophin-beta cell)is proposed. In this signal pathway, under the condition of muscle stimulation, the expression of PGC$1 \alpha$ reveals an obvious increase, thus correspondingly stimulating the expression and cleavage of FNDC5 to generate irisin, activating the expression of UCP1 in the presence of irisin, accelerating the browning of WAT, increasing energy consumption and promoting the regeneration of insulin, as well as completing the rebuilding of beta cells which can initiate a novel strategy for the treatment of diabetes (6). The aim of the work was to estimate the effect of exercise on serum irisin and fasting blood glucose levels in normal and diabetic rats.

\section{Materials and Methods}

This experimental study was done inPhysiology department, Faculty of medicine, Sohag University the study period was 4 months (more or less).This study was carried out in accordance with the guidelines of the University Animal Ethics and approved by Research Ethics Committee considering care and use of

\section{1) Materials} laboratory animals.

120 adult male albino rats (10-12) weeks old about 200-250 gm. body weight, were purchased from Faculty of Science, Sohag University and were housed in Medical Animal Laboratory in Sohag faculty of medicine, animals gained free access to food and tap water.Rats were housed in groups of 8metal cages $(20 \times 32 \times 20 \mathrm{~cm})$ at normal light $/$ dark cycle and room temperature. The study was approved by Research Ethics Committee considering care and use of laboratory animals.

Alloxan (Sigma-Aldrich, St. Louis, MO, USA) was purchased for induction of diabetes. Irisinwas measured by Rat Irisin ELISA kit supplied by SinoGeneClon Biotech co., Ltd (catalog NO:SG-20179).Fastingblood

glucosewas measured using a blood glucose meter (Johnson\& Johnson, New Jersey, USA)with a blood drop from the tail vein.Insulin was measured using ELISA kit (mouse insulin Elisa, Alpco, Salem, NH) ,Catalog Number: 80INSMS-E01,E10.All kits were used according to manufacturer's instructions.

\section{2) Method of the study:}

The 120 rats were divided into 4 groups (I, II, III, IV) equal in number $(n=30)$. Animals were left for one week for accommodation.

GroupI (GI), control sedentary (CS):30 normal adult rats were used as a control group, and were intraperitoneally (IP) injected with physiological saline $(0.9 \% \mathrm{Nacl})$ in adose of $160 \mathrm{ml} / \mathrm{kg}$ in a single dose at the $1^{\text {st }}$ day of the experiment and then stayed in sedentary life style for 8 successive weeks.

GroupII (GII), control exercise (CE): 30 normal adult rats were (IP) injected at the $1^{\text {st }}$ day of the experiment with physiological saline $(0.9 \% \mathrm{Nacl})$ in adose of $160 \mathrm{ml} / \mathrm{kgin}$ a single dose then were undergo swimming exercise for 5 days a week for 8 successive weeks in a barrel filled with water to a depth of $40-50 \mathrm{~cm}$, which allowed free swimming at 33-35 ${ }^{\circ} \mathrm{C}$. The duration of the first swimming 
exercise was limited to $15 \mathrm{~min}$ and increased by $5 \mathrm{~min}$ daily up to $30 \mathrm{~min}$.

GroupIII (GIII), Diabetic sedentary (DS):30 adult rats were overnight fasted, then were (IP) injected at the $1^{\text {st }}$ day of the experiment with freshly prepared alloxan monohydrate $(160 \mathrm{mg} / \mathrm{kg})$ in a single dose for induction of diabetes. To prevent initial alloxan-induced fatal hypoglycemia, each rat was given $2 \mathrm{ml}$ glucose $(10 \%)$ by gavage, in addition to (5\%) glucose in drinking water for the next 24 hours (7). Rats then stayed in a sedentary life style for 8 weeks.

Group IV (G IV) ,Diabetic exercise(DE):30 adult rats were (IP) injected at the $1^{\text {st }}$ day of the experiment withfreshly prepared alloxan monohydrate $(160 \mathrm{mg} / \mathrm{kg})$ in a single dose for induction of diabetes then they were undergo swimming exercise as in GII.

After 48 hours from alloxan injection fasting blood glucose (FBG) levels were checked in blood samples taken from the tail veins. FBG equal or greater than 200 $\mathrm{mg} / \mathrm{dl}$ indicatesdiabetes(7).Fasting blood glucose levels were measured through skin puncture in tail veins weekly for each rat.

At the end of the experiment all rats were anesthetized and a blood sample was taken from the heart of each animal. Blood samples were kept in $37^{\circ} \mathrm{C}$ water bath for 30 minutes to enhance coagulation then centrifuged at $3000 \mathrm{rpm}$ for 10 minutes, serum samples were separated and preserved at $-20{ }^{\circ} \mathrm{C}$ till the time of biochemical assay

Statistical analysis

Data was analyzed using SPSS computer program version 24. Quantitative data was expressed as mean \pm standard deviation. Qualitative data was expressed as number and percentage. The data was tested for normality using Shapiro-Wilk test which was significant indicating the use of nonparametric tests as data wasn't normally distributed. The nonparametric Mann-Whitney U test, Wilcoxon Signed Ranks test and Kruskal-Wallis test were used. Spearman's correlation was used for testing of correlation between different quantitative variables. $\mathrm{P}<.05$ was considered significant in all statistical tests used in the study.

\section{Results}

a) Measures of fasting blood glucose levelin the 1st and 8th week in each group:

Results of this study showed that exercise had lowering effect on blood glucose in diabetic rats.Sedentary life had a worsing effect on blood glucose level in diabetic rats as detected by statistically significant increase in FBG levelin GIII at the end of the $8^{\text {th }}$ week as compared with that at the end of the $1^{\text {st }}$ week (table 1 ).

While exercise had lowering effect on FBG level as shown by statistically significant decrease in FBG in GIV at the end of the $8^{\text {th }}$ when compared with that at the end of the $1^{\text {st }}$ week in the same group as summarized in table 1.

\section{b) Measures of serum level of insulin:}

Insulin levels were higher in control groups than their corresponding diabetic groups as shown by statistically significant elevated level of serum insulin levels in GI and GII as compared with GIII and GIV respectively.

Results of this study revealed that exercise increased serum insulin level in both control and diabetic groups as detected by statistically significant elevated levels of serum insulin in GII and GIV as compared with GI and GIII respectively as summarized in table 2.

\section{c) Measures of serum level of irisin:}


Irisin levels were higher in control groups than their corresponding diabetic groups as shown by statistically significant elevated level of serum irisin levels in GI and GIIas compared with GIII and GIV respectively.

Results of this study revealed that exerciseincreased serum irisin level in both control and diabetic groups as detected by statistically significant elevated levels of serum irisin in GII and GIV as compared with GI and GIII respectively as summarized in table 3.

\begin{tabular}{||c|c|c|c||}
\hline Parameter & $\begin{array}{c}\text { Glucose }(\mathrm{mg} / \mathrm{dl}) \\
\text { in the } 1^{\text {st }} \text { week }\end{array}$ & $\begin{array}{l}\text { Glucose }(\mathrm{mg} / \mathrm{dl}) \\
\text { in the } 8^{\text {th }} \text { week }\end{array}$ & P-value \\
\hline $\begin{array}{c}\text { Groups I(CS) } \\
\text { Mean } \pm \text { S.D. }\end{array}$ & $82.8 \pm 15.9$ & $85.43 \pm 14.43$ & 0.094 \\
\hline $\begin{array}{c}\text { Group II(CE) } \\
\text { Mean } \pm \text { S.D. }\end{array}$ & $83.5 \pm 16.8$ & $83.9 \pm 18.01$ & 0.909 \\
\hline $\begin{array}{c}\text { Group III(DS) } \\
\text { Mean } \pm \text { S.D. }\end{array}$ & $233.9 \pm 20.4$ & $248.57 \pm 18.92$ & $0.001^{*}$ \\
\hline $\begin{array}{c}\text { Group IV(DE) } \\
\text { Mean } \pm \text { S.D. }\end{array}$ & $226 \pm 17.2$ & $158.7 \pm 17.1$ & $0.001^{*}$ \\
\hline \hline
\end{tabular}

Table (1): Fasting blood glucose level (mg/dl) in the $1^{\text {st }}$ and $8^{\text {th }}$ week in each group

Data are expressed as mean \pm standard deviation

P- Value was calculated by Wilcoxon Signed Ranks Test *statistically significant (p $<0.05)$

\begin{tabular}{|l|c|c|c|c|c|c|c||}
\hline $\begin{array}{l}\text { Groups } \\
\text { Parameter }\end{array}$ & $\begin{array}{c}\text { Group (I) } \\
(\mathrm{N}=30)\end{array}$ & $\begin{array}{c}\text { Group (II) } \\
(\mathrm{N}=30)\end{array}$ & $\begin{array}{c}\text { Group (III) } \\
(\mathrm{N}=30)\end{array}$ & $\begin{array}{c}\text { Group (IV) } \\
(\mathrm{N}=30)\end{array}$ & P1 & P2 & P3 \\
\hline \hline $\begin{array}{l}\text { Insulin } \\
(\mathrm{ng} / \mathrm{dl})\end{array}$ & $28.9 \pm 1.7$ & $30.3 \pm 1.4$ & $5.1 \pm 0.6$ & $10.9 \pm 2.3$ & $\mathbf{0 . 0 0 2 *}$ & $<0.001 *$ & $<0.001 *$ \\
\hline \hline
\end{tabular}

Table (2): Comparison of serum insulin level $(\mu \mathrm{U} / \mathrm{mL})$ among the study groups at the end of the study

Data are expressed as mean \pm standard deviation

P1 compared control exercise group (II) versus control sedentary group (I)

P2 compared diabetic exercise group (IV) versus diabetic sedentary group (III) and

P3 compared diabetic exercise group (IV) versus control exercise group (II)

P1, P2, P3 was calculated by Mann-Whitney test*Statistically significant ( $p$ value $<.05$ ) 


\begin{tabular}{|l|c|c|c|c|c|c|c||}
\hline $\begin{array}{c}\text { Groups } \\
\text { Parameter }\end{array}$ & $\begin{array}{c}\text { Group (I) } \\
(\mathrm{N}=30)\end{array}$ & $\begin{array}{c}\text { Group (II) } \\
(\mathrm{N}=30)\end{array}$ & $\begin{array}{c}\text { Group (III) } \\
(\mathrm{N}=30)\end{array}$ & $\begin{array}{c}\text { Group (IV) } \\
(\mathrm{N}=30)\end{array}$ & P1 & P2 & P3 \\
\hline \hline $\begin{array}{l}\text { Irisin } \\
(\mathrm{pg} / \mathrm{ml})\end{array}$ & $\mathbf{2 7 . 3 \pm 6 . 3}$ & $74.8 \pm 9.7$ & $\mathbf{1 2 . 8} \pm \mathbf{3 . 9}$ & $52.1 \pm 7.2$ & $<0.001 *$ & $<0.001 *$ & $<0.001 *$ \\
\hline \hline
\end{tabular}

Table (3): Comparison of serum irisin level (pg/ml) among the study groups at the end of the study.

Data are expressed as mean \pm standard deviation

P1 compared control exercise group (II) versus control sedentary group (I)

P2 compared diabetic exercise group (IV) versus diabetic sedentary group (III)

P3 compared diabetic exercise group (IV) versus control exercise group (II)

P1, P2, P3 was calculated by Mann-Whitney test

*Statistically significant (p value $<0.05$

\section{Discussion}

Exercise, along with diet and weight control, is considered essential for the prevention and management of diabetes (8).

It is well known that physical activity or regular exercise is an excellent way for health promotion; however, its exact molecular mechanisms are still unclear (8).

Irisin is released from muscle tissue in response to exercise. It is the secretion portion of FNDC5 protein and is able to promote the beige of WAT and prevent or inhibit many metabolic diseases in both human and mice (9).

Estimation of blood glucose level showed that exercise has decreasing effect on fasting blood glucose in diabetic rats.

Diabetic sedentary group (GIII) reported a statistically significant increase in mean blood glucose level in the $8^{\text {th }}$ week when compared with mean blood glucose level in the $1^{\text {st }}$ week. On the other hand diabetic exercise group (GIV) reported statistically significant decrease in mean blood glucose level in the $8^{\text {th }}$ week when compared to the mean blood glucose in the $1^{\text {st }}$ week.

This indicates that exercise has decreasing effect on blood glucose of diabetic rats This improvement in glucose can be explained by increased glucose uptake combined with reduced gluconeogenesis and stimulation of glycogenesis through activation of glycogen synthase in the liver(10) alsoirisin can induce GLUT 4 expression and translocation to the cell membrane(11).

Estimation of serum insulin level showed that exercise increase serum insulin level in both control and diabetic groups also showed that insulin was statistically significant high in control than in diabetic groups. This indicates that exercise has increasing effect on insulin hormone of in control and diabetic rats.

This improvement in serum insulin level by exercise may be attributed to the new hypothesis of signaling pathway (p38PGC- $1 \alpha$-irisin-betatrophin- beta cell). In this signal pathway, under the condition of muscle stimulation, the expression of PGC- $1 \alpha$ reveals an obvious increase, correspondingly stimulating the expression and cleavage of FNDC5 to generate irisin, activating the expression of UCP1 in the presence of irisin, accelerating the browning of WAT, 
increasing energy consumption and promoting the regeneration of insulin, as well as completing the rebuilding of beta cells which result in increased serum insulin level in both control exercise and diabetic exercise groups (6).

In this study measurement of serum irisin showed statistically significant increase in control exercise and diabetic exercise when compared with control sedentary and diabetic sedentary respectively also showed statistically significant decrease in serum irisin in diabetic exercise when compared with normal exercise group. It was found that exercise induced PGC-1 $\alpha$ expression in skeletal muscle, which promoted FNDC5 expression, following which FNDC5 was spliced in vivo to irisin. Such results were also reported by $(5,12)$.

\section{Conclusion}

These beneficial observations, which were discussed abovemay explain the mechanism by which exercise can control diabetes mellitus side by side with pharmacological treatment.The molecular mechanisms of irisin in human still have many debates. Therefore, further studies are highly necessary.For example, the identification and functions of irisin receptors, characteristics, signal transduction pathway of irisin need to be further explored, irisin like hormones may exist, and their functions should be explored, and the interaction or cross talk of irisin and other oxygen species.

\section{References}

1)Angelis $\mathrm{K}$ De, Irigoyen MC, Morris $M$ (2009): Diabetes and cardiovascular autonomic dysfunction. Auton.Neurosci. 145, 3-10.

2)Dunstan D. (2011): Diabetes: exercise and T2DM-move muscles more often! Nat. Rev. Endocrinol. 7, 189-190
3)Ravussin E and Galgani JE (2011): The implicationof brown adipose tissue for humans. Annu. Rev. Nutr.31, 33-47.

4)Zhou Z, Yon Toh S, Chen Z, Guo K, Ng C P, Ponniah S, Lin S C, Hong W, Li (2003):.Cidea-deficient mice have lean phenotype and are resistant to obesity. Nat. Genet. 35, 456.

5)Boström P, Wu J , Jedrychowski M P, Korde A, Ye L, Lo J C, Rasbach K A, Boström E A, Choi J H, Long J Z, Kajimura S, Zingaretti MC, Vind BF, Tu H, Cinti S, Højlund K, Gygi S P, Spiegelman BM (2012): A PGC1- $\alpha$ dependent myokine that drives brown-fatlike development of white fat and thermogenesis. Nature, 481, 463-468.

6) Sanchis-Gomar F, Perez-Quilis C (2014): The p38-PGC-1alpha-irisinbetatrophin axis: exploring new pathways in insulin resistance. Adipocyte . 3(1): 6768.

7)Szkudelski $T$ (2001): The mechanism of alloxan and streptozotocin action in $\beta$ cells of rat pancreas. Physiology Research Journal, 50:536-546.

$\begin{array}{lcr}\text { 8) Lackland } & \text { DT, Voeks } & \text { JH } \\ \text { (2014): } \text { Metabolic } & \text { syndrome } & \text { and }\end{array}$ hypertension: regular exercise as part of lifestyle management. CurrHypertens Rep 16(11): 492.

9) Yang $M$, Peihong Chen, Hua Jin, XinmiaoXie, Ting Gao, Lili Yang , XuemeiYuEmail author (2014):Circulating levels of irisin in middle-aged first-degree relatives of type 2 diabetes mellitus correlation with pancreatic B-cell function. Diabetol.Metab.Syndr. 6, 133 .

10) Liu T Y, Shi CX1, Gao R1, Sun HJ1, Xiong XQ1, Ding L1, Chen Q2, Li YH2, Wang JJ1, Kang YM3, Zhu GQ4 (2015):Irisin inhibits hepatic gluconeogenesis and increases glycogen synthesis via the PI3K/Akt pathway in type 2 diabetic mice and hepatocytes. Clin. Sci. (Lond.) 129, 839-850 .

11) Huh J Y , Mougios V, Kabasakalis A, Fatouros I, Siopi A, Douroudos II, Filippaios A, Panagiotou G, Park KH, Mantzoros CS(2014): Exercise-induced 
irisin secretion is independent of age or fitness level and increased irisin may directly modulate muscle metabolism through AMPK activation. J. Clin. Endocrinol.Metab. 99, E2154-E2161

12) Kanaley JA, Timothy D. Heden, Ying Liu,1 Adam T. Whaley-Connell, AnandChockalingam, Kevin C, Dellsperger, Timothy J. Fairchild (2014): Short term aerobic exercise training increases postprandial pancreatic polypeptide but not peptide YY concentrations in obese individuals. Int $\mathbf{J}$ Obes (Lond), 38(2): 266-271. 